\title{
Differentiation between 6- and 7-Membered Rings Based on Theoretical Calculation of NMR Parameters
}

\author{
Karel D. Klika \\ Department of Chemistry, University of Turku, Vatselankatu 2, 20014 Turku, Finland \\ Correspondence should be addressed to Karel D. Klika, klikakd@yahoo.co.uk
}

Received 29 August 2012; Accepted 3 October 2012

Academic Editors: J. Casado, J.-H. Choi, D. Ferri, I. P. Gerothanassis, G. S. Kumar, and J. M. Saniger

Copyright ( $) 2012$ Karel D. Klika. This is an open access article distributed under the Creative Commons Attribution License, which permits unrestricted use, distribution, and reproduction in any medium, provided the original work is properly cited.

The determination of ring size can vary from simple to complex, but the process in difficult cases can be advantageously augmented by DFT calculation of NMR parameters such as the chemical shifts of ${ }^{1} \mathrm{H}\left(\delta_{\mathrm{H}}\right),{ }^{13} \mathrm{C}\left(\delta_{\mathrm{C}}\right)$, and other nuclei as well as pertinent spinspin (scalar) coupling constants, for example, those between protons $\left(J_{\mathrm{H}, \mathrm{H}}\right)$. Differentiation between 6- and 7-membered ring formation in the case of 3,4-dihydro-2H-3-hydroxymethyl-1,4-benzoxazine and 2,3,4,5-tetrahydro-1,5-benzoxazepine-3-ol was evaluated with a view to not only affecting 6- versus 7-membered ring differentiation generally for cases on hand, but also in the case of literature reports where the assigned structures may be in doubt. Thus, the main focus was on the usually reported NMR parameters of $\delta_{\mathrm{H}}, \delta_{\mathrm{C}}$, and $J_{\mathrm{H}, \mathrm{H}}$ and wherein the analysis was found to be highly successful, particularly for $\delta_{\mathrm{C}}$, and thus potentially amenable for broad application.

\section{Introduction}

Obviously the determination of ring size in the framework of organic compounds is a crucial and basic precept in structural chemistry, whether the compounds in question arose through synthetic processes or were obtained from natural sources. The distinction between, for example, 6and 7-membered rings can, in particular cases, be surprisingly difficult even by the application of sophisticated NMR experiments [1]. Evermore so in heterocyclic systems where the availability of suitable hydrogen atoms within or proximal to the cyclic unit for analysis may be limitedwhether concerning either solely ${ }^{1} \mathrm{H}$ nuclei or ${ }^{1} \mathrm{H}$ nuclei in conjunction with other nuclei, for example, ${ }^{13} \mathrm{C}$, the problems and challenges of discerning between 5- and 6membered rings in heterocyclic systems with a deficient number of ${ }^{1} \mathrm{H}$ nuclei by NMR have been considered [1] previously in depth using DFT calculations based on the consideration of various NMR parameters as depicted in Figure 1. For example, the chemical shifts of nuclei such as ${ }^{1} \mathrm{H}\left(\delta_{\mathrm{H}}\right),{ }^{13} \mathrm{C}\left(\delta_{\mathrm{C}}\right)$, and ${ }^{15} \mathrm{~N}\left(\delta_{\mathrm{N}}\right)$; various spin-spin (scalar) coupling constants between nuclei such as ${ }^{1} \mathrm{H}$ and ${ }^{1} \mathrm{H}\left(J_{\mathrm{H}, \mathrm{H}}\right)$, ${ }^{1} \mathrm{H}$ and ${ }^{13} \mathrm{C}\left(J_{\mathrm{H}, \mathrm{C}}\right)$, and ${ }^{1} \mathrm{H}$ and ${ }^{15} \mathrm{~N}\left(J_{\mathrm{H}, \mathrm{N}}\right)$; NOEs between nuclei such as ${ }^{1} \mathrm{H}$ and ${ }^{1} \mathrm{H}\left(\eta_{\mathrm{H}, \mathrm{H}}\right)$ and ${ }^{1} \mathrm{H}$ and ${ }^{13} \mathrm{C}\left(\eta_{\mathrm{H}, \mathrm{C}}\right)$. The prediction of NMR parameters $[2,3]$ such as chemical shifts, but especially coupling constants, has come of age recently in terms of development and practical application [4-6], and especially with respect to conformational analysis [7-9].

We herein complement the previous study of 5- versus 6-membered ring formation with the consideration of 6- and 7-membered ring differentiation using as a basis for the study the pair of compounds, 3,4-dihydro- $2 \mathrm{H}-3$ hydroxymethyl-1,4-benzoxazine (1) and 2,3,4,5-tetrahydro1,5-benzoxazepine-3-ol (2), presented in Figure 2. The chosen pair is notable and of interest for a number of reasons: the assigned structures of $\mathbf{1}$ have been erroneously reported (vide infra) which has come to light only very recently [12]; the compounds are important synthons [12]; they are interesting models for structural studies, in particular, conformational analysis [13]; furthermore, they and their analogs have had significant biological activities reported $[12,14]$; finally, they belong to pharmacologically important compound classes [12].

In addition to solving this somewhat persistent problem as an example of the wider application of DFT-calculated NMR parameters such as $\delta_{\mathrm{H}}, \delta_{\mathrm{C}}$, and $J_{\mathrm{H}, \mathrm{H}}$ for differentiating 


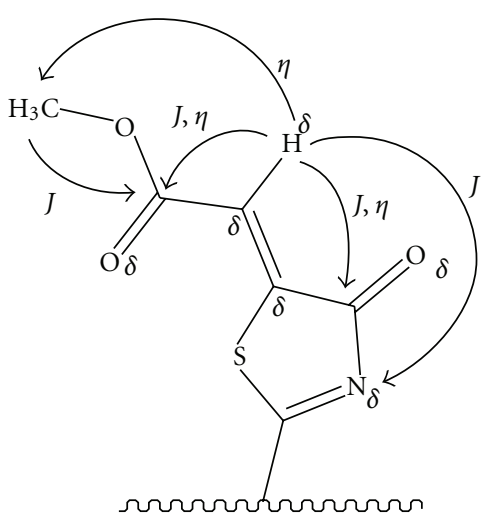

(a)

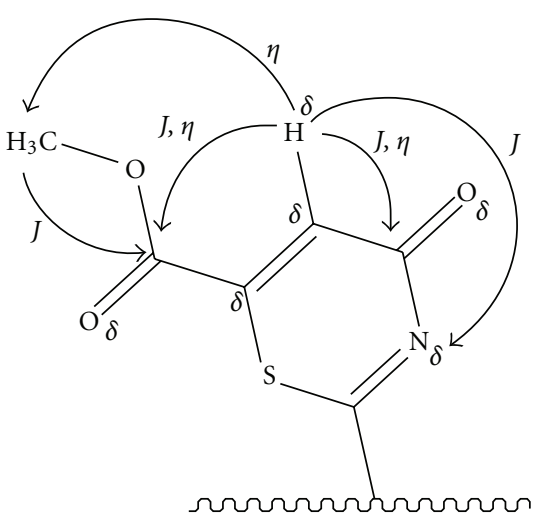

(b)

FIGURE 1: Depiction of various NMR parameters considered in a previous study [1] for rendering distinction between 5- and 6-membered ring products, namely, 1,3-thiazolidin-4-one and 1,3-thiazin-4-one products, respectively, obtained [10, 11] from 2-substituted 1-(9acridinyl) thiosemicarbazides by reagent selection (dimethyl acetylenedicarboxylate in the former case and methyl propiolate in the latter case).

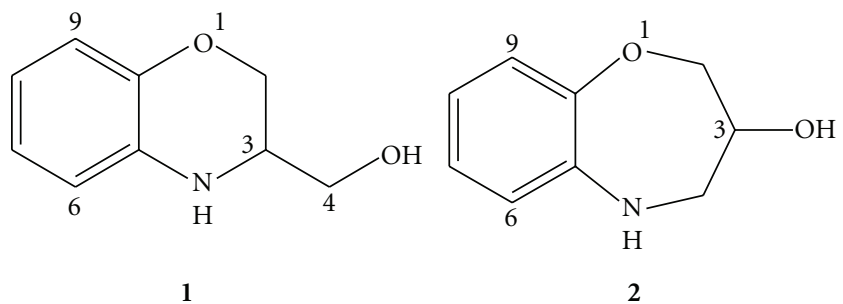

FIGURE 2: The structures of the 6-membered ring product 3,4dihydro-2H-3-hydroxymethyl-1,4-benzoxazine (1) and the isomeric 7-membered ring product 2,3,4,5-tetrahydro-1,5-benzoxazepine-3-ol (2). The unconventional atomic numbering indicated for $\mathbf{1}$ is to facilitate direct, and thus convenient, comparisons of the nuclei with 2 .

between 6- and 7-membered rings, the question arises, what if workers do not have recourse to performing the NMR measurements? This may not necessarily be because workers do not have access to suitable instrumentation, but because they do not have the compounds on hand, either at present or in the foreseeable future. Workers may, akin to the case of García-Rubiño et al. [12], be contemplating a synthesis, or, alternatively, workers may not even be intent on physically procuring the compounds as they may be undergoing structure-activity relationships (SARs) or docking studies in the absence of physical measurements altogether and be hoping to use the ensuing results to explain past observations or predict future directions for work. Hence, in this examination we focus primarily on the basic NMR data which is generally available in the literature, namely, the chemical shifts of ${ }^{1} \mathrm{H}\left(\delta_{\mathrm{H}}\right)$ and ${ }^{13} \mathrm{C}$ nuclei $\left(\delta_{\mathrm{C}}\right)$ and the ${ }^{1} \mathrm{H}-{ }^{1} \mathrm{H}$ spin-spin (scalar) coupling constants $\left(J_{\mathrm{H}, \mathrm{H}}\right)$ even if the structural proofs of the compounds may be highly amenable, even facile, using modern NMR techniques on sophisticated, modern instrumentation. Thus, in order to save the time, effort, and cost of resynthesizing compounds or otherwise procuring them (not to mention avoiding confusion or even the reporting of erroneous results), the current study has been undertaken to examine the particular example case of 6- and 7-membered ring differentiation.

\section{Computational Methods}

DFT quantum chemical calculations were performed using Gaussian09 [15] (version A.01) and analyzed using GaussView (version 3.07). Geometry optimization of the structures in the gas phase was performed using the M06$2 \mathrm{X}$ hybrid metadensity functional $[16,17]$ with the 6$31 \mathrm{G}(\mathrm{d})$ basis set in tandem with vibrational analysis and thermochemistry calculations at the same level of theory. It is worth noting that the use of a modest basis set for structural optimization affords computational efficacy where high structural fidelity is not required to obtain quality results for the subsequent calculation of NMR parameters [4]. Vibrational analyses, invoking the keyword freq = noraman, were conducted to confirm that optimized structures were true minima on the potential energy surface by not providing imaginary frequencies and to obtain the thermodynamic contributions at $298.15 \mathrm{~K}$ and $1 \mathrm{~atm}$ wherein frequencies were left unscaled. If necessitated by the presence of imaginary frequencies, structures were reoptimized (together also with vibrational analyses and thermochemistry calculations) using tight convergence criteria by invoking the keywords $o p t=$ tight and int $=$ ultrafine.

Absolute chemical shieldings and spin-spin coupling constants were calculated for geometry-optimized structures in the gas phase using the GIAO method [18] and the B3LYP functional $[19,20]$ with the cc-pVTZ basis set. Chemical shifts relative to the reference compounds were determined by subtracting calculated shieldings from the calculated shieldings of the reference compounds: TMS for which both $\delta_{\mathrm{H}}$ and $\delta_{\mathrm{C}}=0.00 \mathrm{ppm}$ and $\mathrm{CH}_{3} \mathrm{NO}_{2}$ for which $\delta_{\mathrm{N}}=0.00 \mathrm{ppm}$ and $\delta_{\mathrm{O}}=602.50 \mathrm{ppm}$. The chemical shifts of ${ }^{1} \mathrm{H},{ }^{13} \mathrm{C}$, and 
${ }^{15} \mathrm{~N}$ nuclei were calibrated following literature methodology [21] using the following relationships:

$$
\begin{array}{cc}
\delta_{\mathrm{H}}=0.9736 \times \delta_{\text {calc }}+0.058 & \left(R^{2}=0.9970\right), \\
\delta_{\mathrm{C}}=0.9980 \times \delta_{\text {calc }}-3.780 & \left(R^{2}=0.9987\right), \\
\delta_{\mathrm{N}}=0.9099 \times \delta_{\text {calc }}-10.743 & \left(R^{2}=0.9922\right) .
\end{array}
$$

The calculated $\delta_{\mathrm{O}}$ values were not calibrated. Spin-spin (scalar) coupling constants such as $J_{\mathrm{H}, \mathrm{H}}$ and $J_{\mathrm{H}, \mathrm{C}}$ were calculated by invoking the keyword $n m r=$ spinspin with the calculations incorporating all four contributing termsthe Fermi contact term, paramagnetic and diamagnetic spin-orbit and spin-dipolar terms-despite the increased computational cost of doing so. Coupling constant values obtained from the calculations were used as received and were not corrected.

\section{Results and Discussion}

3.1. Course of the Reaction. The example pair of compounds on which this analysis has been conducted was taken from the recent literature wherein the structure of 3,4dihydro-2H-3-hydroxymethyl-1,4-benzoxazine (1) had been assigned to the products resulting from several different reported reactions $[14,22,23]$. In each case the product was the same despite the varying conditions and different research groups concerned. The correct structure of the resultant compound, in fact, has been shown very recently to be 2,3,4,5-tetrahydro-1,5-benzoxazepine-3-ol (2) by GarcíaRubiño et al. [12] who proved conclusively the structures of compounds 1 and 2 by both the application of NMR methods and synthetic procedures. The problem here is that structures were not originally assigned based on factual NMR measurements and workers inadvertently and unwittingly implied that multiplicity assignments of the ${ }^{13} \mathrm{C}$ had been determined, presumably by the application of some multiplicity determining pulse sequence like the DEPT pulse sequence. It is unclear how the various workers settled on the assigned structures (assumed reaction course perhaps?), but subsequently it was demonstrated rather simply the proof [12] of the structures of 1 and 2 by readily available means to most chemists, namely, by DEPT and HMBC NMR experiments. Despite the ready and straightforward means to affect distinction, the erroneous structural assignments have, disparagingly, perpetuated [22, 23].

The reaction at hand, in various guises, is essentially composed of intramolecular nucleophilic attack by an amino group on a monosubstituted 1,2-epoxide as depicted in Scheme 1. By Baldwin's [24] rules for ring closure, both routes are feasible processes, 6-exo-tet to lead to 1 and 7-exotet to lead to 2 . The reaction is interesting as it compares $1^{\circ}$ versus $2^{\circ}$ attack to yield 7 - or 6-membered rings, respectively. Thus the result is a confluence of thermodynamic constraints (a 6- or a 7-membered ring with the former generally preferred and borne out by calculations in this instance) versus kinetic factors $\left(1^{\circ}\right.$ or $2^{\circ}$ attack) versus proximity of the reacting centers. Thus, it is not necessarily a surprise that both compounds could be produced in comparable amounts depending on the reaction conditions applied [12]. Interestingly, the original source of the error may have come from work on a 6-aza analogue of 1, 4-acetyl-3-(hydroxymethyl)3,4-dihydro- $2 \mathrm{H}$-pyrido[3,2-b] oxazine, prepared in a similar fashion to the preparation reported by Jiao et al. [14] and where too the workers [25] not only seem to have made the same inadvertent error regarding the multiplicities of the carbons, but have also made an unsound presumption regarding the course of the reaction. In that case, a $2^{\circ}$ amide supposedly displaces an oxygen from a mono-substituted 1,2 -epoxide group, not at the $1^{\circ}$ carbon, but instead at the $2^{\circ}$ carbon, to form the product. Unfortunately, there must now be grave doubt regarding the correctness of that structure [25] as well.

3.2. Conformational Analysis and Molecular Modeling. For compound 1, two half-chair conformations are possible for a 6-membered alicyclic fused to a benzene ring [8] with the $-\mathrm{CH}_{2} \mathrm{OH}$ group adopting either axial or equatorial orientations. Additionally, the $\mathrm{NH}$ proton can potentially also adopt either axial or equatorial orientations, and finally, rotation about the $\mathrm{CH}-\mathrm{CH}_{2} \mathrm{OH}$ (i.e., $\mathrm{C}_{3}-\mathrm{C}_{4}$ ) and $\mathrm{CH}_{2}-\mathrm{OH}$ bonds is also possible (3 rotamers each). Altogether then, $2 \times 2 \times 3 \times 3=36$ conformations are conceivable. The former two mobilities were fully explored but for the latter two bond rotations, judicious selection based on hydrogen bonding opportunities and steric congestion considerations, as well as also taking into account the preference for a gauche disposition [26] between N-5 and O-4 (the "gauche effect"), was used to limit the number of structures examined. Altogether, 6 low-energy conformers $\left({ }^{2} \mathrm{H}_{3}\right)$ were located for 1 (Table 1); that is, 5 other conformers were within $2 \mathrm{kcal} \mathrm{mol}^{-1}$ of the global minimum energy conformer. Whilst the global minimum incorporated a hydrogen bond and a $-\mathrm{CH}_{2} \mathrm{OH}$ group that was equatorially oriented, of the other 5 low-energy conformers each with an axially oriented $-\mathrm{CH}_{2} \mathrm{OH}$ group, 2 conformers involved intramolecular hydrogen bonding of HO-4 whilst another 2 involved HN-5. The remaining conformer lacked intramolecular hydrogen bonding altogether. In 5 conformers, the $\mathrm{NH}$ proton was equatorially oriented whilst in the remaining conformer it was isoclinal. The two lowest-energy structures for compound 1 are presented in Figures 3 and 4.

Other high-energy structures were not included in the ensuing calculation of NMR parameters since their contribution is negligible (well less than 5\%) and thus only conformers within $2 \mathrm{kcal} \mathrm{mol}^{-1}$ of the global minimum energy conformer were considered for further analysis, and in this instance, the global minimum energy conformer accounts for ca. $65 \%$ of the population. In line with expectations, intramolecularly hydrogen bonding structures were generally lower in energy, although surprisingly, one nonhydrogen bonded structure did rank amongst these lowenergy structures. Even more surprising, it did not have a gauche interaction either. Of note, it is well known that intramolecularly hydrogen-bonded structures can persist in solution, even in $\mathrm{CDCl}_{3}$. Indeed, the observation of a $2 \mathrm{H}$ broad singlet-presumably the $\mathrm{NH}$ and $\mathrm{OH}$ protons-by 


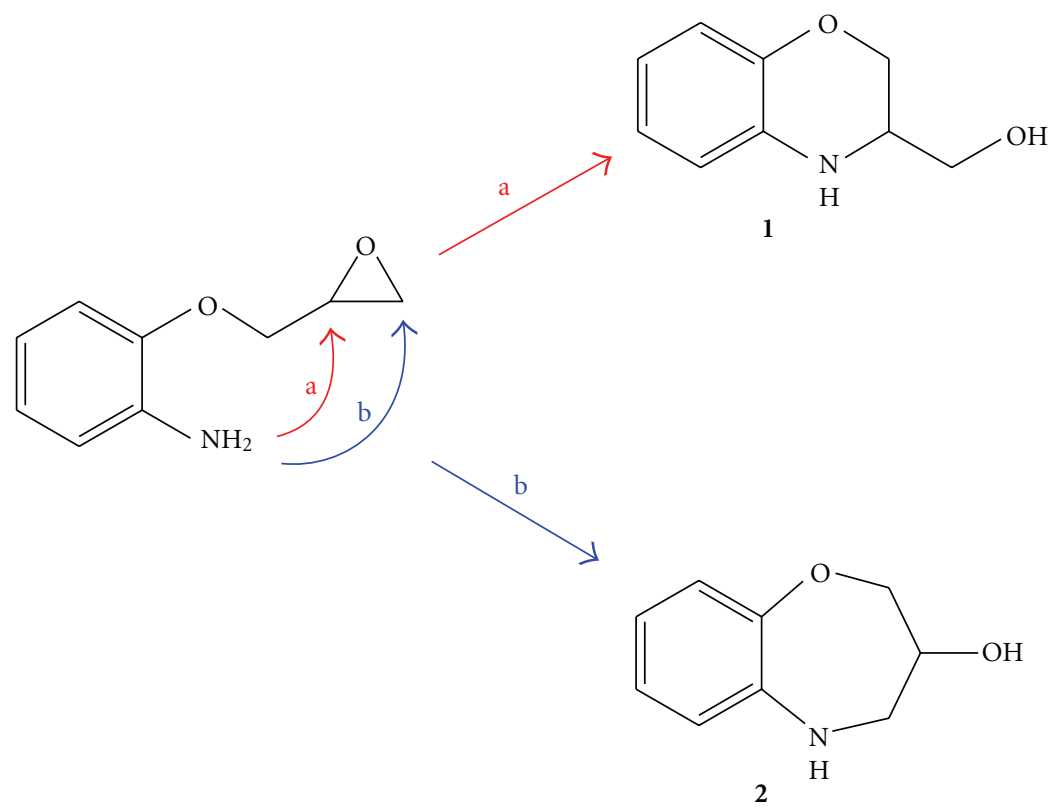

Scheme 1: Simplified reaction scheme indicating the pathway leading to products 1 and $\mathbf{2}$ from the amino epoxide intermediate produced in situ.

TAble 1: The low-energy conformations, their Gibbs' free energies, and other structural information found for compounds 1 and 2.

\begin{tabular}{|c|c|c|c|c|c|c|}
\hline \multirow[t]{2}{*}{$\begin{array}{l}\text { Compound, } \\
\text { conformer }^{\mathrm{a}}\end{array}$} & \multicolumn{2}{|c|}{$\begin{array}{l}\text { Group orientations } \\
\text { and configurations }{ }^{\mathrm{a}}\end{array}$} & \multirow[t]{2}{*}{$\begin{array}{l}\text { Hydrogen bonding of } \\
\mathrm{OH}: \rightarrow \text { atom, } r(\AA)\end{array}$} & \multirow[t]{2}{*}{$\begin{array}{l}\text { gauche interactions of } \\
\text { O- } 4 \text { with: }\end{array}$} & \multirow[t]{2}{*}{$\Delta G\left(\mathrm{kcal} \mathrm{mol}^{-1}\right)$} & \multirow[t]{2}{*}{$\begin{array}{l}\text { Boltzmann } \\
\text { population (\%) }\end{array}$} \\
\hline & O group ${ }^{\mathrm{b}}$ & $\mathrm{NH}$ & & & & \\
\hline \multicolumn{7}{|c|}{ Compound 1} \\
\hline $1,{ }^{2} \mathrm{H}_{3}$ & equatorial, $\beta$ & equatorial, $\alpha$ & $\mathrm{N}, 2.25$ & $\mathrm{~N}$ & $0.00^{c}$ & 64.7 \\
\hline $2,{ }^{2} \mathrm{H}_{3}$ & axial, $\alpha$ & isoclinal, $\beta$ & $\mathrm{N}, 2.26$ & $\mathrm{~N}$ & 0.93 & 13.5 \\
\hline $3,{ }^{2} \mathrm{H}_{3}$ & axial, $\alpha$ & equatorial, $\alpha$ & $\mathrm{NH} \rightarrow \mathrm{OH}, 2.43$ & $\mathrm{~N}$ & 1.06 & 10.8 \\
\hline $4,{ }^{2} \mathrm{H}_{3}$ & axial, $\alpha$ & equatorial, $\alpha$ & $\mathrm{NH} \rightarrow \mathrm{OH}, 2.53$ & $\mathrm{~N}$ & 1.66 & 3.9 \\
\hline $5,{ }^{2} \mathrm{H}_{3}$ & axial, $\alpha$ & equatorial, $\alpha$ & none & none & 1.71 & 3.6 \\
\hline $6,{ }^{2} \mathrm{H}_{3}$ & axial, $\alpha$ & equatorial, $\alpha$ & $\mathrm{O}, 2.10$ & $\mathrm{~N}$ & 1.73 & 3.5 \\
\hline \multicolumn{7}{|c|}{ Compound 2} \\
\hline $1,{ }^{3} \mathrm{C}=$ & axial, $\beta$ & equatorial, $\alpha$ & $\mathrm{N}, 2.38 ; \mathrm{O}, 2.48$ & $\mathrm{~N}, \mathrm{O}$ & $0.00^{c}$ & 90.1 \\
\hline $2,{ }^{2} \mathrm{~TB}_{4}$ & isoclinal, $\beta$ & equatorial, $\alpha$ & $\mathrm{N}, 2.45$ & $\mathrm{~N}$ & 1.61 & 5.9 \\
\hline $3,{ }^{2} \mathrm{~TB}_{4}$ & isoclinal, $\alpha$ & equatorial, $\alpha$ & $\mathrm{O}, 2.54$ & $\mathrm{O}$ & 1.85 & 4.0 \\
\hline
\end{tabular}

${ }^{a}$ Due to symmetry, the change in configuration at C-3 effected in the constructs of $\mathbf{1}$ and $\mathbf{2}$ during conformational searching is only enantiomeric and not diastereomeric and no further consideration needs to be accounted for. Structures, however, are described as presented with no reference to the actual enantiomer calculated (thus, mixed enantiomers are present). Diastereotopic proton designations, though, are corrected for this to enable correct comparison of the same nuclei in Tables $2-5{ }^{b}-\mathrm{CH}_{2} \mathrm{OH}$ in the case of $\mathbf{1} ; \mathrm{OH}$ in the case of $2{ }^{\mathrm{c}}$ The global minimum of 1 was $1.82 \mathrm{kcal} \mathrm{mol}^{-1}$ lower in energy in comparison to the global minimum of 2 .

Jiao et al. [14] is an indication of this for these compounds since if intermolecularly hydrogen-bonded structures only were present, then the $\mathrm{NH}$ and $\mathrm{OH}$ protons would likely be so broad as to be unobservable, as it is generally the case for $\mathrm{CDCl}_{3}$ solutions of compounds with labile protons.

7-Membered rings present a challenge in terms of conformational analysis which is generally substantially greater in comparison to 6-membered rings [13] due to additional conformational flexibility and a larger number of conformers that reside close in energy. For a 7-membered ring fused to an aromatic ring, chair $(C)$ and twist-boat (TB) conformers are acknowledged [13] as being the preferred conformers, with the former much more so but this can be altered substantially depending on the particular case of a substituent at C-5 [13]. For 7-membered ring 2, the search protocol followed similarly to that for the 6membered ring 1 and consisted of starting with one handbuilt structure, for example, a chair, optimizing the structure and then using the result as a template for the construction of subsequent structures. Likewise, the first permutation 




FIGURE 3: The DFT-calculated structure of the global minimum energy conformation $\left({ }^{2} \mathrm{H}_{3}\right)$ of compound 1 .

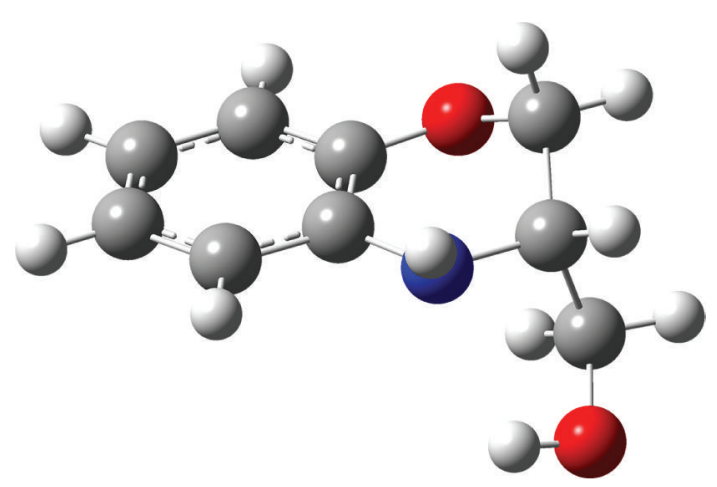

FIGURE 4: The DFT-calculated structure of the second-lowest energy conformation $\left({ }^{2} \mathrm{H}_{3}\right)$ of compound 1 .

considered was a change of the $\mathrm{OH}$ group to the other isoclinal/axial orientation by simply switching the $\mathrm{OH}$ and $\mathrm{H}$ moieties on C-3. Then, for each of these two structures, axial and equatorial orientations of the $\mathrm{NH}$ group were evaluated. Since the $-\mathrm{CHOH}$ segment is part of the ring, rotations about the $\mathrm{C}_{2}-\mathrm{CHOH}$ and $\mathrm{CHOH}-\mathrm{C}_{4}$ bonds to yield various gauche interactions and hydrogen bonding possibilities were not possible without changing the ring conformation. Incidentally, for 2 , two gauche interactions are possible, even simultaneously, from the disposition of the $\mathrm{OH}$ group to the N-5 and O-1 atoms in comparison to $\mathbf{1}$. The same process was repeated starting from a twist-boat conformation. Of these $2 \times 2 \times 2=8$ constructs, possibilities for hydrogen bonding (and alternatively, not) were examined by rotation about the $\mathrm{C}_{3}-\mathrm{OH}$ bond. Boat conformations were also examined but comparable low-energy structures were not located. By this means, a total of three lowenergy conformations, one chair $\left({ }^{3} \mathrm{C}_{=}\right)$, and two twist boats $\left({ }^{2} \mathrm{~TB}_{4}\right)$, were found (Table 1$)$ with the chair conformation, as expected, overwhelmingly dominant ( $>90 \%$ populated). Interestingly, in this conformation, a three-center hydrogen bond is formed and this conformation is further stabilized by two gauche interactions. The other two conformations each incorporated one hydrogen bond and one gauche interaction. Again, likewise to 1, in all these three conformations, the $\mathrm{NH}$ proton was equatorially oriented. The two lowest-energy structures for compound 2 are presented in Figures 5 and 6.

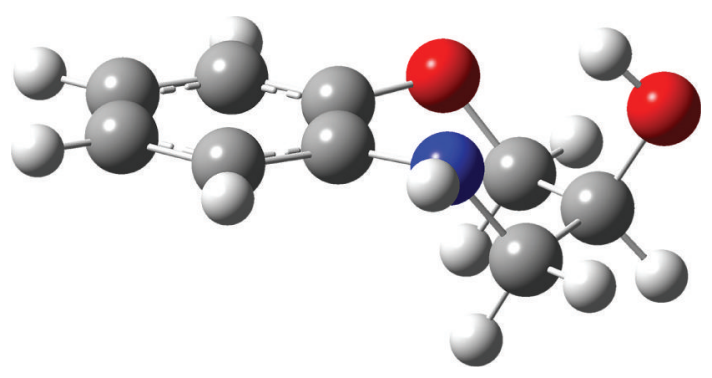

FIGURE 5: The DFT-calculated structure of the lowest energy conformation $\left({ }^{3} \mathrm{C}_{=}\right)$of compound 2 .

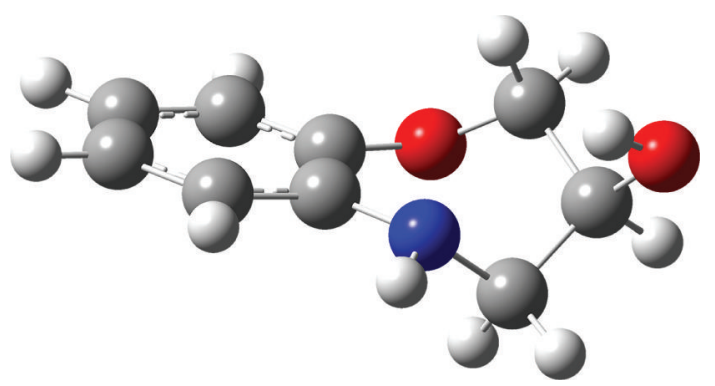

FIGURE 6: The DFT-calculated structure of the second-lowest energy conformation $\left({ }^{2} \mathrm{~TB}_{4}\right)$ of compound 2 .

It must be said that, somewhat paradoxically, the 7membered ring compound 2 was more acquiescent to conformational analysis than the 6-membered ring compound 1 in this case.

3.3. Analysis of the Calculated NMR Parameters. The $\delta_{\mathrm{H}} \mathrm{s}$ of the labile protons HO-4 and HN-5 were not evaluated since they are usually highly variable in nature as they are very dependent on concentration, temperature, solvetic hydrogen bonding, and other environmental influences, as well as dynamic exchange effects yielding shifted or averaged chemical shifts. Moreover, since it is difficult to account for intermolecular hydrogen bonding, the $\mathrm{CH}-\mathrm{CH}_{2} \mathrm{OH}$ and $\mathrm{CH}_{2}-\mathrm{OH}$ bond rotations in compound 1 and the $\mathrm{CH}_{2}-$ $\mathrm{OH}$ bond rotation in compound $\mathbf{2}$ are not considered very reliable in terms of conformational analysis. Fortunately, the rotations were not found to be influential on the geometry of the $-\mathrm{O}-\mathrm{CH}_{2}-\mathrm{CH}-$ fragment in $\mathbf{1}$ and thus, the -O$\mathrm{CH}_{2}-\mathrm{CH}-$ spin system in $\mathbf{1}$ was the primary focus for the analysis whilst the full $-\mathrm{O}-\mathrm{CH}_{2}-\mathrm{CH}-\mathrm{CH}_{2}-$ spin system was considered in 2 . The calculated $\delta_{\mathrm{H}} \mathrm{s}$ for all the nonlabile protons together with the experimental $\delta_{\mathrm{H}} \mathrm{s}$ [12] are presented in Table 2 wherein it can be seen that the calculated $\delta_{\mathrm{H}} \mathrm{s}$ in relation to the observed $\delta_{\mathrm{H}} \mathrm{s}$ are in fair agreement but not strongly indicative of the assigned structure. With both compounds on hand, a valued judgment could easily be made, for example, $\delta_{\mathrm{H} 2 \alpha}$ and $\delta_{\mathrm{H} 2} \beta$ and particularly with respect to their difference, but decidedly less if the experimental values of only one compound were available. For example, with only compound $\mathbf{1}$ available, an erroneous assignment could easily be made based on $\delta_{\mathrm{H} 3}$. This is not 
TABLe 2: DFT-calculated and experimental ${ }^{1} \mathrm{H}$ NMR chemical shifts $\left(\delta_{\mathrm{H}} / \mathrm{ppm}\right)$ for $\mathbf{1}$ and 2.

\begin{tabular}{|c|c|c|c|c|c|c|c|c|c|c|}
\hline Cmpd, conf. & & H-2 $2 \alpha$ & $\mathrm{H}-2 \beta$ & $\mathrm{H}-3$ & $\mathrm{H}-4 \alpha^{\mathrm{a}}$ & $\mathrm{H}-4 \beta^{\mathrm{a}}$ & H-6 & $\mathrm{H}-7$ & H-8 & H-9 \\
\hline \multirow{8}{*}{1} & 1 & 4.24 & 4.10 & 3.26 & 3.55 & 3.67 & 6.67 & 6.80 & 6.81 & 6.84 \\
\hline & 2 & 4.03 & 3.70 & 3.09 & 3.67 & 3.30 & 6.81 & 6.89 & 6.87 & 6.87 \\
\hline & 3 & 3.96 & 4.25 & 3.27 & 4.08 & 3.65 & 6.56 & 6.78 & 6.66 & 6.71 \\
\hline & 4 & 3.92 & 4.29 & 3.15 & 4.04 & 3.46 & 6.53 & 6.77 & 6.69 & 6.75 \\
\hline & 5 & 4.61 & 3.97 & 3.17 & 3.46 & 4.12 & 6.39 & 6.72 & 6.63 & 6.76 \\
\hline & 6 & 4.26 & 4.22 & 2.98 & 4.21 & 3.72 & 6.55 & 6.84 & 6.62 & 6.76 \\
\hline & PWA & 4.19 & 4.07 & 3.22 & 3.66 & 3.63 & 6.66 & 6.81 & 6.78 & 6.82 \\
\hline & exp. [12] & $4.18^{\mathrm{b}}$ & $4.06^{\mathrm{b}}$ & 3.55 & $3.72^{\mathrm{b}}$ & $3.64^{\mathrm{b}}$ & $6.63^{\mathrm{b}}$ & 6.76 & $6.65^{\mathrm{b}}$ & 6.76 \\
\hline \multirow{5}{*}{2} & 1 & 4.26 & 3.32 & 3.40 & 3.20 & 2.75 & 6.79 & 6.97 & 6.97 & 7.10 \\
\hline & 2 & 3.62 & 4.35 & 3.87 & 2.87 & 3.99 & 6.53 & 6.85 & 6.75 & 6.89 \\
\hline & 3 & 4.00 & 4.56 & 3.76 & 3.22 & 3.37 & 6.46 & 6.81 & 6.74 & 6.89 \\
\hline & PWA & 4.21 & 3.43 & 3.45 & 3.18 & 2.85 & 6.76 & 6.96 & 6.94 & 7.08 \\
\hline & exp. [12] & $4.25^{\mathrm{b}}$ & $3.86^{\mathrm{b}}$ & 3.93 & $3.36^{\mathrm{b}}$ & $3.17^{\mathrm{b}}$ & 6.75 & 6.89 & 6.82 & 6.99 \\
\hline
\end{tabular}

Legend: PWA, population-weighted average. ${ }^{\mathrm{a}}$ In the case of 2 ; proR and proS, respectively, for $1 .{ }^{\mathrm{b}}$ Assignments assumed with respect to the (near) neighboring value.

TABLe 3: DFT-calculated and experimental ${ }^{13} \mathrm{C}$ NMR chemical shifts $\left(\delta_{\mathrm{C}} / \mathrm{ppm}\right)$ for $\mathbf{1}$ and 2.

\begin{tabular}{|c|c|c|c|c|c|c|c|c|c|c|}
\hline Cmpd, conf. & & $\mathrm{C}-2$ & C-3 & C-4 & C-5a & $\mathrm{C}-6$ & $\mathrm{C}-7$ & $\mathrm{C}-8$ & C-9 & C-9a \\
\hline \multirow{8}{*}{1} & 1 & 67.0 & 52.0 & 62.9 & 135.3 & 117.1 & 121.6 & 121.7 & 118.0 & 148.1 \\
\hline & 2 & 63.8 & 56.7 & 60.4 & 131.5 & 120.6 & 122.5 & 122.4 & 119.0 & 148.7 \\
\hline & 3 & 65.0 & 52.2 & 62.1 & 134.5 & 116.8 & 122.4 & 119.3 & 117.5 & 147.2 \\
\hline & 4 & 64.1 & 51.3 & 60.4 & 133.6 & 115.2 & 122.3 & 119.7 & 117.7 & 147.3 \\
\hline & 5 & 62.6 & 51.7 & 62.1 & 134.9 & 114.3 & 122.0 & 119.0 & 117.8 & 147.0 \\
\hline & 6 & 69.9 & 52.3 & 71.8 & 139.3 & 115.1 & 124.0 & 118.1 & 117.6 & 147.6 \\
\hline & PWA & 66.2 & 52.6 & 62.6 & 134.8 & 117.3 & 121.9 & 121.3 & 118.1 & 148.0 \\
\hline & exp. [12] & 66.1 & 51.4 & 63.0 & 132.9 & 116.1 & 121.9 & 119.3 & 116.9 & 144.1 \\
\hline \multirow{5}{*}{2} & 1 & 76.0 & 67.9 & 54.2 & 146.9 & 120.1 & 124.9 & 123.7 & 124.1 & 156.7 \\
\hline & 2 & 76.0 & 69.0 & 52.9 & 143.2 & 117.3 & 123.7 & 121.2 & 122.4 & 153.1 \\
\hline & 3 & 76.1 & 71.3 & 53.5 & 143.3 & 117.0 & 123.7 & 120.7 & 121.8 & 151.8 \\
\hline & PWA & 76.0 & 68.1 & 54.1 & 146.6 & 119.8 & 124.8 & 123.5 & 123.9 & 156.3 \\
\hline & exp. [12] & 75.4 & 68.6 & 52.4 & 142.0 & 120.0 & 124.1 & 122.1 & 122.2 & 150.7 \\
\hline
\end{tabular}

Legend: PWA, population-weighted average.

too surprising as $\delta_{\mathrm{H}} \mathrm{s}$ are known to be problematic in relation to $\delta_{\mathrm{C}} \mathrm{s}$ which are known to be reliable indicators $[6,9]$ of structure. Unexpectedly, $\delta_{\mathrm{H} 4 \alpha}$ and $\delta_{\mathrm{H} 4 \beta}$ are much better predicted in $\mathbf{1}$ than in $\mathbf{2}$ despite the above concerns. The aromatic $\delta_{\mathrm{H}} \mathrm{s}$ provide a reasonable indication and though they are not unequivocal, they nevertheless do insinuate correct assignment, and moreover, could do so even if only one compound was available.

The calculated $\delta_{\mathrm{C}}$ s for the carbon nuclei together with the experimental $\delta_{\mathrm{C}} \mathrm{s}[12]$ are presented in Table 3 wherein it can be seen that the calculated $\delta_{\mathrm{C}} \mathrm{s}$ are in excellent agreement with the observed $\delta_{\mathrm{C}} \mathrm{s}$ and would convincingly enable the correct structural assignment to be made-even in the event of only one isomer being available. The $\delta_{\mathrm{C} 2}, \delta_{\mathrm{C} 3}, \delta_{\mathrm{C} 4}, \delta_{\mathrm{C} 5 \mathrm{a}}$, and $\delta_{\mathrm{C} 9 \mathrm{a}}$ results are particularly emphatic, but a similar assessment also holds for the aromatic carbons that are not in common with the heterocycle (i.e., $\delta_{\mathrm{C} 6}, \delta_{\mathrm{C} 7}, \delta_{\mathrm{C} 8}$, and $\delta_{\mathrm{C} 9}$ ). Of particular note, the structural determination can readily be done even without the assignment of the carbons experimentally.
The calculated $J_{\mathrm{H}, \mathrm{H}} \mathrm{S}$ for the protons of the alicyclic ring together with their experimental analogous $J_{\mathrm{H}, \mathrm{H}} \mathrm{S}$ [12] are presented in Table 4 . The calculated vicinal couplings ${ }^{3} J_{\mathrm{H} 2 \alpha, \mathrm{H} 3}$ and ${ }^{3} J_{\mathrm{H} 2 \beta, \mathrm{H} 3}$ in relation to the observed values are in excellent agreement and would convincingly enable the correct structural assignment to be accomplished, again even if only one compound was available. The situation, however, with the ${ }^{3} J_{\mathrm{H} 3, \mathrm{H} 4 \alpha}$ and ${ }^{3} J_{\mathrm{H} 3, \mathrm{H} 4 \beta}$ couplings is slightly more complicated, the values for 2 are in excellent agreement with the experimental values but those for 1 , in concert with the aforementioned concerns, are not. Nevertheless, with due appreciation of the factors concerned, correct analysis can be effected if either both compounds were on hand or even if only one was available. The geminal couplings, ${ }^{2} J_{\mathrm{H} 2 \alpha, \mathrm{H} 2 \beta}$ and ${ }^{2} J_{\mathrm{H} 4 \alpha, \mathrm{H} 4 \beta}$, were disappointing and do not provide any sort of indication of the correct structure. The long-range couplings were all evaluated as negligible, consistent with observations, except for ${ }^{4} J_{\mathrm{H} 2 \alpha, \mathrm{H} 4 \alpha}$ in compound 2 which was calculated to be $1.5 \mathrm{~Hz}$ in magnitude. This is in fine agreement with the 
TABLE 4: DFT-calculated and experimental homonuclear ${ }^{1} \mathrm{H}-{ }^{1} \mathrm{H}$ NMR spin-spin (scalar) coupling constants $\left(J_{\mathrm{H}, \mathrm{H}} / \mathrm{Hz}\right)$ for 1 and 2 in the alicyclic ring.

\begin{tabular}{|c|c|c|c|c|c|c|c|c|c|c|c|}
\hline Cmpd, conf. & & $\begin{array}{c}\mathrm{H}-2 \alpha, \\
\mathrm{H}-2 \beta\end{array}$ & $\begin{array}{c}\text { H-2 } \alpha, \\
\text { H-3 }\end{array}$ & $\begin{array}{c}\mathrm{H}-2 \beta, \\
\mathrm{H}-3\end{array}$ & $\begin{array}{c}\mathrm{H}-3, \\
\mathrm{H}-4 \alpha^{\mathrm{a}}\end{array}$ & $\begin{array}{c}\mathrm{H}-3, \\
\mathrm{H}-4 \beta^{\mathrm{a}}\end{array}$ & $\begin{array}{l}\mathrm{H}-4 \alpha \\
\mathrm{H}-4 \beta^{\mathrm{a}}\end{array}$ & $\begin{array}{l}\mathrm{H}-2 \alpha, \\
\mathrm{H}-4 \alpha^{\mathrm{a}}\end{array}$ & $\begin{array}{l}\text { H- } 2 \alpha, \\
\text { H- } 4 \beta^{\text {a }}\end{array}$ & $\begin{array}{l}\mathrm{H}-2 \beta, \\
\mathrm{H}-4 \alpha^{\mathrm{a}}\end{array}$ & $\begin{array}{l}\mathrm{H}-2 \beta, \\
\mathrm{H}-4 \beta^{\mathrm{a}}\end{array}$ \\
\hline \multirow{8}{*}{1} & 1 & -9.50 & 7.54 & 2.82 & 1.19 & 2.79 & -10.01 & -0.13 & -0.69 & 0.16 & -0.25 \\
\hline & 2 & -9.34 & 1.28 & 2.72 & 9.46 & 4.28 & -9.14 & -0.02 & 0.27 & -0.65 & -0.26 \\
\hline & 3 & -9.38 & 1.95 & 2.41 & 9.13 & 3.15 & -5.94 & -0.12 & 0.26 & -0.66 & -0.16 \\
\hline & 4 & -9.37 & 1.91 & 2.32 & 9.78 & 4.85 & -10.48 & -0.07 & 0.17 & -0.63 & -0.45 \\
\hline & 5 & -8.71 & 2.12 & 1.98 & 4.14 & 9.31 & -5.62 & -0.62 & -0.26 & 0.68 & -0.62 \\
\hline & 6 & -9.24 & 1.84 & 2.32 & 0.90 & 3.72 & -10.82 & 0.24 & 0.01 & 0.10 & 2.36 \\
\hline & PWA & -9.42 & 5.48 & 2.70 & 3.60 & 3.38 & -9.34 & -0.12 & -0.38 & -0.05 & -0.17 \\
\hline & $\begin{array}{l}\text { exp. } \\
{[12]}\end{array}$ & -10.8 & $5.9^{\mathrm{b}}$ & $2.9^{\mathrm{b}}$ & $4.9^{\mathrm{b}}$ & $7.1^{b}$ & -10.7 & no & no & no & no \\
\hline \multirow{5}{*}{2} & 1 & -10.00 & 3.46 & 0.85 & 4.52 & 1.29 & -9.97 & 1.53 & 0.04 & -0.03 & 0.44 \\
\hline & 2 & -10.88 & 7.76 & 7.08 & 2.02 & 2.32 & -10.98 & -0.44 & -0.35 & 0.23 & -0.55 \\
\hline & 3 & -10.55 & 0.93 & 2.61 & 7.91 & 7.46 & -11.34 & -0.41 & 0.38 & -0.36 & -0.48 \\
\hline & PWA & -10.08 & 3.62 & 1.29 & 4.51 & 1.60 & -10.08 & 1.34 & 0.03 & -0.03 & 0.35 \\
\hline & $\begin{array}{l}\text { exp. } \\
{[12]}\end{array}$ & -12.3 & $3.8^{\mathrm{b}}$ & $2.0^{\mathrm{b}}$ & $4.9^{\mathrm{b}}$ & $2.4^{\mathrm{b}}$ & -12.9 & 1.4 & no & no & no \\
\hline
\end{tabular}


neighboring value. ${ }^{b}$ Assignments arbitrary and can be interchanged with the neighboring value.

TABLE 5: Selected DFT-calculated three-bond heteronuclear ${ }^{1} \mathrm{H}-{ }^{13} \mathrm{C}$ NMR spin-spin (scalar) coupling constants $\left({ }^{3} J_{\mathrm{H}, \mathrm{C}} / \mathrm{Hz}\right.$ ) ${ }^{15} \mathrm{~N}$ NMR chemical shifts $\left(\delta_{\mathrm{N}} / \mathrm{ppm}\right)$, and ${ }^{17} \mathrm{O}$ NMR chemical shifts $\left(\delta_{\mathrm{O}} / \mathrm{ppm}\right)$ for $\mathbf{1}$ and $\mathbf{2}$.

\begin{tabular}{|c|c|c|c|c|c|c|c|c|c|}
\hline Cmpd, conf & & $\mathrm{H}-2 \alpha, \mathrm{C}-9 \mathrm{a}$ & $\mathrm{H}-2 \beta, \mathrm{C}-9 \mathrm{a}$ & $\mathrm{H}-3, \mathrm{C}-5 \mathrm{a}$ & $\mathrm{H}-4 \alpha,{ }^{\mathrm{a}} \mathrm{C}-5 \mathrm{a}$ & $\mathrm{H}-4 \beta,{ }^{\mathrm{a}} \mathrm{C}-5 \mathrm{a}$ & $\delta_{\mathrm{N} 5}$ & $\delta_{\mathrm{O} 1}$ & $\delta_{\mathrm{O} 3 / 4}$ \\
\hline \multirow{7}{*}{1} & 1 & 0.22 & 6.93 & 0.02 & 1.26 & -0.03 & -312.1 & -1.6 & -87.0 \\
\hline & 2 & 6.41 & 0.35 & 4.30 & -0.03 & -0.18 & -329.7 & -3.2 & -77.1 \\
\hline & 3 & 6.76 & 0.16 & 5.64 & 0.02 & -0.21 & -317.1 & -6.9 & -77.2 \\
\hline & 4 & 6.59 & -0.01 & 5.75 & 0.01 & -0.20 & -318.7 & -6.3 & -81.7 \\
\hline & 5 & 7.06 & 0.24 & 5.39 & -0.02 & 0.04 & -313.4 & -9.5 & -75.2 \\
\hline & 6 & 6.68 & 0.67 & 5.06 & -0.01 & -0.08 & -310.6 & -4.8 & -68.5 \\
\hline & PWA & 2.48 & 4.58 & 1.80 & 0.81 & -0.07 & -315.3 & -3.0 & -83.4 \\
\hline \multirow{4}{*}{2} & 1 & 1.00 & 0.36 & -0.03 & 1.05 & 0.39 & -324.3 & -11.8 & -61.5 \\
\hline & 2 & 4.28 & 7.17 & -0.21 & 6.78 & 3.44 & -322.3 & 0.9 & -49.2 \\
\hline & 3 & 6.56 & 3.89 & -0.07 & 3.75 & 7.00 & -315.6 & -16.8 & -43.3 \\
\hline & PWA & 1.42 & 0.90 & -0.04 & 1.50 & 0.83 & -323.9 & -11.3 & -60.0 \\
\hline
\end{tabular}

Legend: PWA, population-weighted average. ${ }^{\mathrm{a}}$ In the case of 2 ; proR and proS, respectively, for $\mathbf{1}$.

measured value of $1.4 \mathrm{~Hz}$ and arises from the $\omega$-disposition of these two protons in the dominant ${ }^{2} \mathrm{H}_{3}$ chair conformer (90\%).

García-Rubiño et al. [12] also reported that whilst correlations from the $\mathrm{H}-2 \mathrm{~s}$ to $\mathrm{C}-9 \mathrm{a}$ were observed in the $\mathrm{HMBC}$ spectra for both compounds 1 and 2 (i.e., the ${ }^{3} J_{\mathrm{H} 2, \mathrm{C} 9 \mathrm{a}} \mathrm{S}$ must be sizeable, e.g., a few $\mathrm{Hz}$ at least in magnitude for each compound), only for 2 could correlations from protons of the heterocyclic ring be observed to $\mathrm{C}-5 \mathrm{a}$, and these were from the $\mathrm{H}-4 \mathrm{~s}$, thus unequivocally proving its structure. This is because the ${ }^{3} J_{\mathrm{H} 4, \mathrm{C} 5 \mathrm{a}} \mathrm{s}$ in 2 extending over three bonds were expected to be sizeable whereas the ${ }^{4} J_{\mathrm{H} 4, \mathrm{C} 5 \mathrm{a}} \mathrm{S}$ in $\mathbf{1}$ extending over four bonds were not. From the calculations (Table 5), these surmises-which are considered in general as truisms-are well supported, but unexpectedly not by the population-weighted averaged (PWA) values which are small for all of ${ }^{3} J_{\mathrm{H} 2 \alpha, \mathrm{C} 9 \mathrm{a}},{ }^{3} J_{\mathrm{H} 2 \beta, \mathrm{C} 9 \mathrm{a}},{ }^{3} J_{\mathrm{H} 4 \alpha, \mathrm{C} 5 \mathrm{a}}$, and ${ }^{3} J_{\mathrm{H} 4 \beta, \mathrm{C} 5 \mathrm{a}}$ in compound 2 and ${ }^{3} J_{\mathrm{H} 2 \alpha, \mathrm{C} 9 \mathrm{a}}$ in compound $\mathbf{1}$ despite clear correlations being observed in each case. Evidently the conformer interconversion must be relatively slow on the NMR timescale to allow the development of antiphase magnetization in the HMBC spectrum during the initial delay time (typically ca. $60 \mathrm{~ms}$ if a $J_{\mathrm{H}, \mathrm{C}}$ of $8 \mathrm{~Hz}$ is desired for optimum observation) for creation of multiple quantum magnetization due to the large $J$ values present in the minor conformers. Thus, the correlations observed [12], with the exception of $\mathrm{H}-2 \beta-\mathrm{C}-9 \mathrm{a}$, in fact arise from the minor conformers (ca. $24 \%$ and ca. $10 \%$ for 1 and 2, resp.). Enigmatically then, acquiring the $\mathrm{HMBC}$ spectrum at lower temperature could lead to a reduction in peak intensity due to a lowering of the content of the minor conformers whilst acquiring the $\mathrm{HMBC}$ spectrum at higher temperature 
could also lead to a reduction in peak intensity due to fast interconversion of the conformers leading to a PWA $J$ value being in effect. Of note though, large values were neither calculated for ${ }^{4} J_{\mathrm{H} 4 \alpha, \mathrm{C} 5 \mathrm{a}}$ nor for ${ }^{4} J_{\mathrm{H} 4 \beta, \mathrm{C} 5 \mathrm{a}}$ in any of the conformations for compound $\mathbf{1}$.

Although García-Rubiño et al. [12] did not measure ${ }^{15} \mathrm{~N}$ NMR spectra, they are also likely to be indicative of the structures obtained based on the calculated values of $\delta_{\mathrm{N} 5}$ (Table 5) where the chemical shift difference for $\delta_{\mathrm{N} 5}$ between compounds 1 and 2 was found to be a sizeable $8.6 \mathrm{ppm}$. The ${ }^{15} \mathrm{~N}$ NMR spectra for compounds $\mathbf{1}$ and $\mathbf{2}$ are likely to be easily measureable, either directly using techniques such as DEPT and INEPT, [27], or indirectly using HSQC since N-5 bears a directly attached proton.

Similarly, though García-Rubiño et al. [12] did not measure ${ }^{17} \mathrm{O}$ NMR spectra, differences were calculated for the two oxygen nuclei present (Table 5). For $\delta_{\mathrm{O} 1}$, the calculated chemical shift difference was actually only marginal, $8.3 \mathrm{ppm}$, given the breadth of the chemical shift range for ${ }^{17} \mathrm{O}$ and the difficulty in measuring $\delta_{\mathrm{O}}$ accurately due to the large breadth of the ${ }^{17} \mathrm{O}$ NMR signals (of the order of several ppm depending on $B_{0}$, etc.). However, for $\delta_{\mathrm{O} 3 / 4}$, the calculated chemical shift difference was a sizeable $23.4 \mathrm{ppm}$, in line with expectations $[28,29]$ for differences between primary and secondary alcohols. Moreover, the chemical shift difference between O-1 and O-3/4 contrasts nicely in the two compounds, $80.4 \mathrm{ppm}$ for compound 1 and $48.7 \mathrm{ppm}$ for compound 2. Thus, as a result of the chemical shift difference of the two oxygen nuclei present in the one molecule, ${ }^{17} \mathrm{O}$ NMR may afford a greater degree of structural reliability over ${ }^{15} \mathrm{~N}$ NMR in this instance. Hence, despite the problems with acquiring ${ }^{17} \mathrm{O}$ NMR data-low sensitivity arising from low $\gamma$, low isotopic abundance, and broad lines thus requiring relatively large sample amounts and/or long acquisition times in addition to the aforementioned accurate determination of $\delta_{\mathrm{O}}$-it could well be decisive and worth the effort.

\section{Conclusions}

In this work, the differentiation between 6- and 7membered ring formation in the case of 3,4-dihydro- $2 \mathrm{H}-3$ hydroxymethyl-1,4-benzoxazine (1) and 2,3,4,5-tetrahydro1,5-benzoxazepine-3-ol (2) was evaluated using DFT calculation of the NMR parameters $\delta_{\mathrm{H}}, \delta_{\mathrm{C}}$, and $J_{\mathrm{H}, \mathrm{H}}$. The point was not only to confirm the correction of the erroneous structural assignments in the literature with respect to these particular compounds, but also with a view to affecting 6versus 7 -membered ring differentiation generally for cases on hand and to add to our methodology for differentiating between 5- and 6-membered ring formation. Since the distinction was readily facilitated in this instance using $\delta_{\mathrm{H}}$ and $\delta_{\mathrm{C}}$ as well as $J_{\mathrm{H}, \mathrm{H}}$, the methodology can thus not only be applied generally, but can also be applied to other cases in the literature where assigned structures may be in doubt. Thus, the structural assignments can be either confirmed or dispelled a priori without wasting valuable time and resources. This is important in cases not only for workers contemplating or undergoing synthetic processes, but also others who may be involved with prospective compounds but not in physical possession of the compounds themselves and be using them for SAR or docking studies in the absence of physical measurements or for literature evaluations. In this particular evaluation, it was found that $\delta_{\mathrm{H}} \mathrm{s}$ were not so reliable, the $J_{\mathrm{H}, \mathrm{H}} \mathrm{s}$ provided mixed results but were reliable if due care was applied, and finally, the $\delta_{\mathrm{C}} \mathrm{s}$ were found to be extremely indicative of the correct structure at hand, even in the absence of experimental data for all candidate structures.

It is also worth bringing to attention several points regarding the obtainment of reliable calculations. Firstly, it is highly important that a systematic search of potential contributing conformational participants be undertaken. Secondly, that sufficient geometry optimization using a reasonable level of theory $[4,5]$ is utilized. In the present day with the computational power available to most practitioners, this can be a quite modest requirement. Thirdly, an appropriate basis set for the NMR parameter calculations $[4,5]$ is also utilized; a large number of conformations need not necessarily be calculated though, just the primary ones accounting for the majority of the populated states. And finally, appropriate treatment of the participating conformers by evaluating population-weighted averages [ 7 , 9] is affected when appropriate.

\section{Acknowledgment}

Thanks are due to The CSC-IT Center for Science Ltd. for providing computational resources.

\section{References}

[1] S. Böhm, J. Tomaščiková, J. Imrich et al., "Computational study to assign structure, tautomerism, $E / Z$ and $s$-cis/s-trans isomerism, $\pi$-delocalization, partial aromaticity, and the ring size of 1,3-thiazolidin-4-ones and 1,3-thiazin-4-ones formed from thiosemicarbazides," Journal of Molecular Structure, vol. 916, no. 1-3, pp. 105-118, 2009.

[2] M. Kaupp, M. Buhl, and V. G. Malkin, Eds., Calculation of NMR and EPR Parameters: Theory and Applications, WileyVCH, Weinheim, Germany, 2004.

[3] T. Helgaker, M. Jaszuński, and K. Ruud, "Ab initio methods for the calculation of NMR shielding and indirect spin-spin coupling constants," Chemical Reviews, vol. 99, no. 1, pp. 293$352,1999$.

[4] A. Bagno, "Complete prediction of the ${ }^{1} \mathrm{H}$ NMR spectrum of organic molecules by DFT calculations of chemical shifts and spin-spin coupling constants," Chemistry, vol. 7, no. 8, pp. 1652-1661, 2001.

[5] A. Bagno, F. Rastrelli, and G. Saielli, "Toward the complete prediction of the ${ }^{1} \mathrm{H}$ and ${ }^{13} \mathrm{C}$ NMR spectra of complex organic molecules by DFT methods: application to natural substances," Chemistry, vol. 12, no. 21, pp. 5514-5525, 2006.

[6] G. Barone, L. Gomez-Paloma, D. Duca, A. Silvestri, R. Riccio, and G. Bifulco, "Structure validation of natural products by quantum-mechanical GIAO calculations of ${ }^{13} \mathrm{C}$ NMR chemical shifts," Chemistry, vol. 8, no. 14, pp. 3233-3239, 2002.

[7] P. Tähtinen, A. Bagno, K. D. Klika, and K. Pihlaja, "Modeling NMR parameters by DFT methods as an aid 
to the conformational analysis of cis-fused $7 \mathrm{a}(8 \mathrm{a})$-methyl octa(hexa)hydrocyclopenta[ $[d][1,3]$ oxazines and $[3,1]$ benzoxazines," Journal of the American Chemical Society, vol. 125, no. 15, pp. 4609-4618, 2003.

[8] K. Pihlaja, P. Tähtinen, K. D. Klika, T. Jokela, A. Salakka, and K. Wähälä, "Experimental and DFT ${ }^{1} \mathrm{H}$ NMR study of conformational equilibria in trans-4',7-dihydroxyisoflavan-4ol and trans-isoflavan-4-ol," Journal of Organic Chemistry, vol. 68, no. 18, pp. 6864-6869, 2003.

[9] G. Barone, D. Duca, A. Silvestri, L. Gomez-Paloma, R. Riccio, and G. Bifulco, "Determination of the relative stereochemistry of flexible organic compounds by ab initio methods: conformational analysis and Boltzmann-averaged GIAO ${ }^{13} \mathrm{C}$ NMR chemical shifts," Chemistry, vol. 8, no. 14, pp. 3240-3245, 2002.

[10] J. Imrich, J. Tomaščková, I. Danihel, P. Kristian, S. Böhm, and K. D. Klika, "Selective formation of 5- or 6-membered rings, 1,3-thiazolidin-4-one versus 1,3-thiazin-4-one, from acridine thiosemicarbazides by the use of ethyne acid esters," Heterocycles, vol. 80, no. 1, pp. 489-503, 2010.

[11] I. Potočák, J. Imrich, I. Danihel, J. Koíšek, and K. D. Klika, "4-(9,10-Dihydroacridin-9-ylidene)thio-semicarbazide and its five-membered thia-zole and six-membered thia-zine derivatives," Acta Crystallographica Section C, vol. 66, no. 2, pp. o87-092, 2010.

[12] M. E. García-Rubiño, M. C. Núñez, M. A. Gallo, and J. M. Campos, "Synthesis, unambiguous chemical characterization, and reactivity of 2,3,4,5-tetrahydro-1,5-benzoxazepines-3-ol," RSC Advances. In press.

[13] A. Entrena, J. M. Campos, M. A. Gallo, and A. Espinosa, "Rules for predicting the conformational behavior of saturated sevenmembered heterocycles," Arkivoc, vol. 2005, no. 6, pp. 88-108, 2005.

[14] P.-F. Jiao, B.-X. Zhao, W.-W. Wang et al., "Design, synthesis, and preliminary biological evaluation of 2,3-dihydro-3hydroxymethyl-1,4-benzoxazine derivatives," Bioorganic and Medicinal Chemistry Letters, vol. 16, no. 11, pp. 2862-2867, 2006.

[15] M. J. Frisch, G. W. Trucks, H. B. Schlegel et al., Gaussian09, Revision A.01. Gaussian, Gaussian, Inc., Wallingford, Conn, USA, 2009.

[16] Y. Zhao and D. G. Truhlar, "The M06 suite of density functionals for main group thermochemistry, thermochemical kinetics, noncovalent interactions, excited states, and transition elements: two new functionals and systematic testing of four M06-class functionals and 12 other functionals," Theoretical Chemistry Accounts, vol. 120, no. 1-3, pp. 215-241, 2008.

[17] Y. Zhao and D. G. Truhlar, "Density functionals with broad applicability in chemistry," Accounts of Chemical Research, vol. 41, no. 2, pp. 157-167, 2008.

[18] K. Wolinski, J. F. Hinton, and P. Pulay, "Efficient implementation of the gauge-independent atomic orbital method for NMR chemical shift calculations," Journal of the American Chemical Society, vol. 112, no. 23, pp. 8251-8260, 1990.

[19] A. D. Becke, "Density-functional thermochemistry-III. The role of exact exchange," The Journal of Chemical Physics, vol. 98, no. 7, pp. 5648-5652, 1993.

[20] C. Lee, W. Yang, and R. G. Parr, "Development of the ColleSalvetti correlation-energy formula into a functional of the electron density," Physical Review B, vol. 37, no. 2, pp. 785789, 1988.

[21] J. Mäki, P. Tähtinen, L. Kronberg, and K. D. Klika, "Restricted rotation/tautomeric equilibrium and determination of the site and extent of protonation in bi-imidazole nucleosides by multinuclear NMR and GIAO-DFT calculations," Journal of Physical Organic Chemistry, vol. 18, no. 3, pp. 240-249, 2005.

[22] Q.-Y. Meng, Q. Liu, J. Li, R.-G. Xing, X.-X. Shen, and B. Zhou, "First use of HEH in oxazine synthesis: hydroxy-substituted 2H-1,4-benzoxazine derivatives," Synlett, no. 20, pp. 32833286, 2009.

[23] B. Zhao, S. Zhang, and P. Jiao, Chinese patent, CN 1847232 A, Appl. No. CN 2006-10043245, 2006.

[24] J. E. Baldwin, "Rules for ring closure," Journal of the Chemical Society, Chemical Communications, no. 18, pp. 734-736, 1976.

[25] N. Henry, G. Guillaumet, and M. D. Pujol, "The first enantioselective synthesis of 4-acetyl-3(R)- and 3(S)-(hydroxymethyl)3,4-dihydro-2H-pyrido[3,2-b] oxazine," Tetrahedron Letters, vol. 45, no. 7, pp. 1465-1468, 2004.

[26] E. L. Eliel and S. H. Wilen, Stereochemistry of Organic Compounds, John Wiley \& Sons, New York, NY, USA, 1994.

[27] K. D. Klika, "Direct detection of non-proton-bearing ${ }^{15} \mathrm{~N}$ nuclei by long-range couplings using polarization transfer," Magnetic Resonance in Chemistry, vol. 48, no. 10, pp. 818-822, 2010.

[28] I. P. Gerothanassis, "Oxygen-17 NMR spectroscopy: basic principles and applications-part I," Progress in Nuclear Magnetic Resonance Spectroscopy, vol. 56, no. 2, pp. 95-197, 2010.

[29] I. P. Gerothanassis, "Oxygen-17 NMR spectroscopy: basic principles and applications-part II," Progress in Nuclear Magnetic Resonance Spectroscopy, vol. 57, no. 1, pp. 1-110, 2010. 


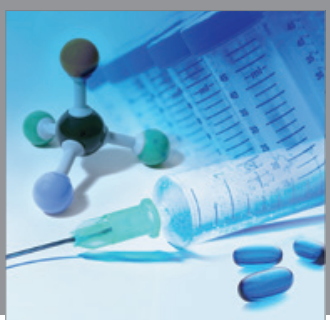

International Journal of

Medicinal Chemistry

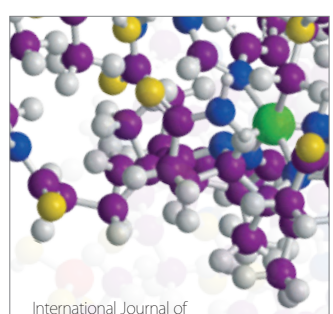

Carbohydrate Chemistry

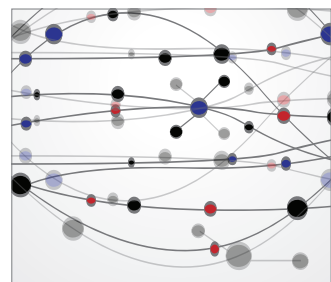

The Scientific World Journal
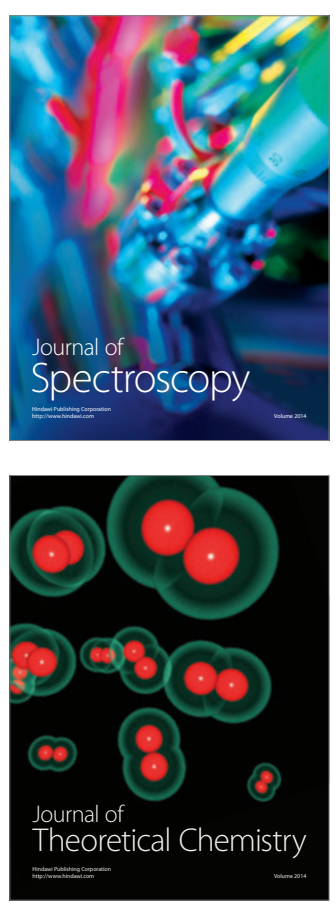
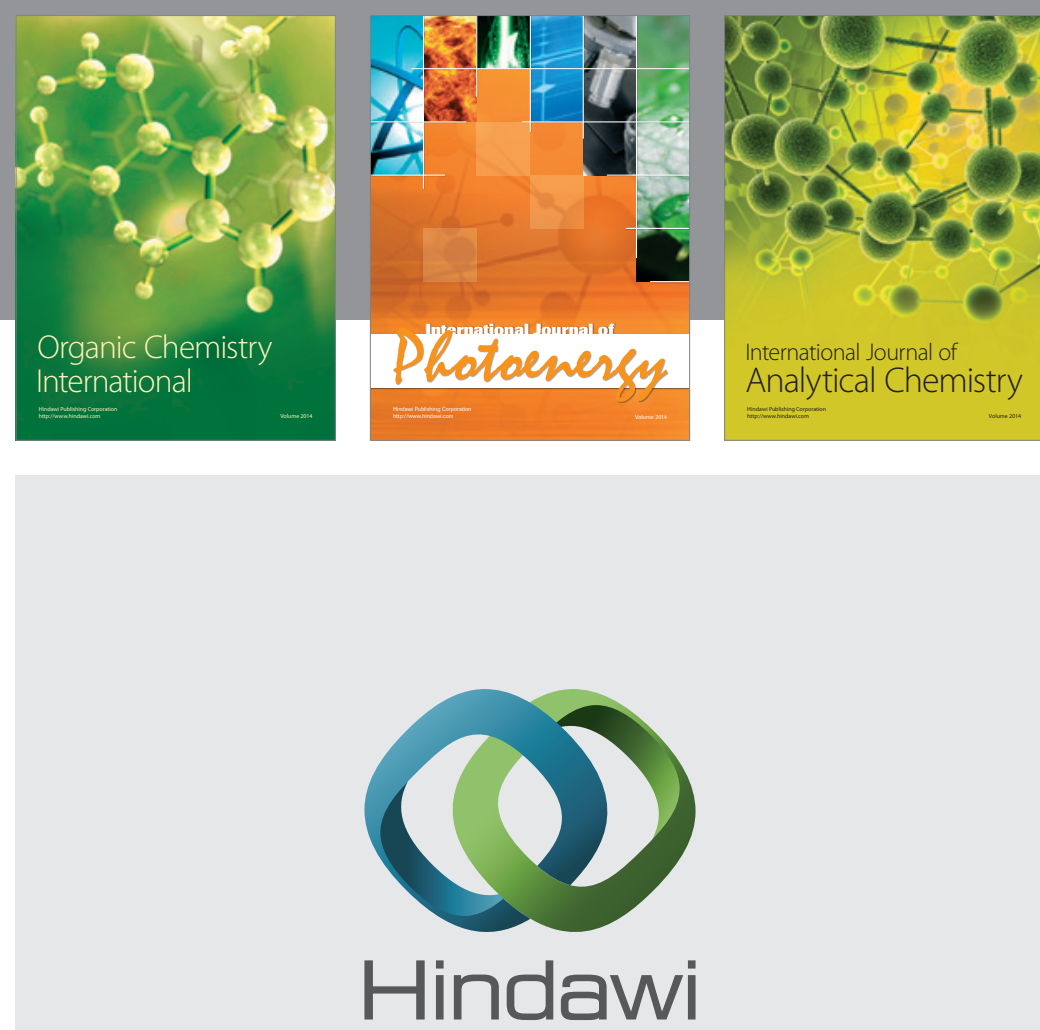

Submit your manuscripts at

http://www.hindawi.com
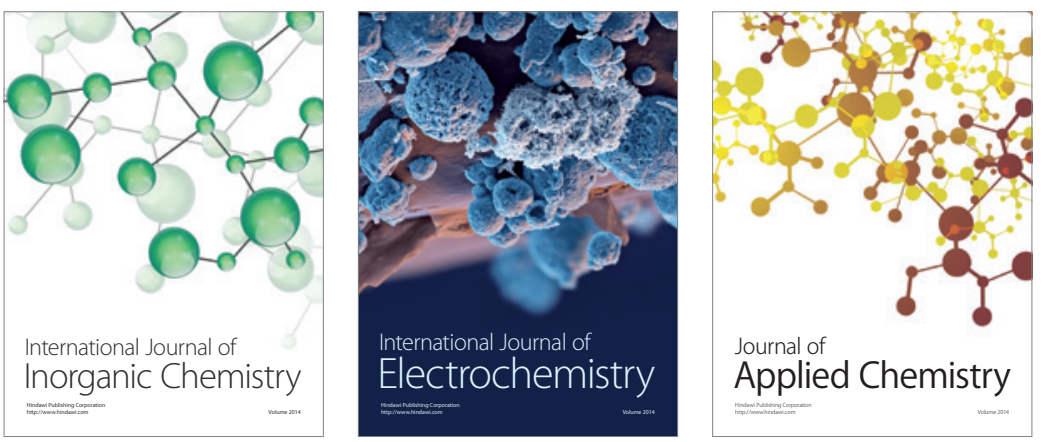

Journal of

Applied Chemistry
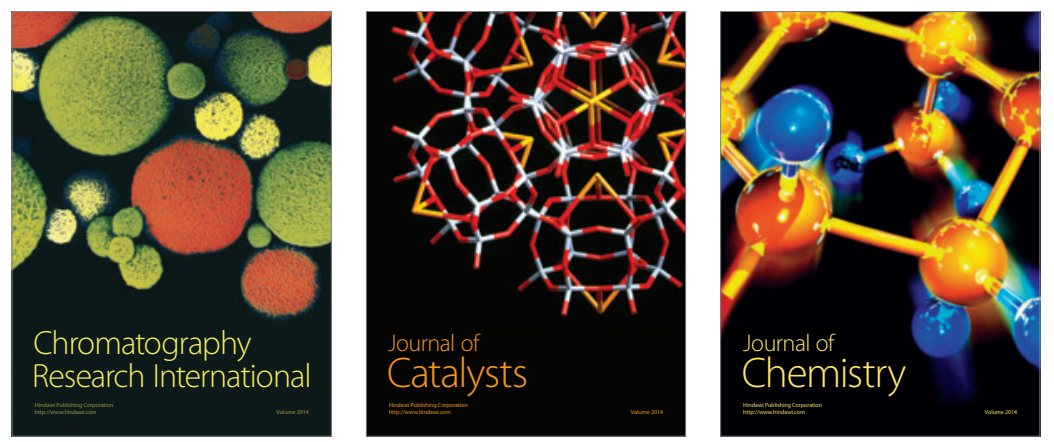
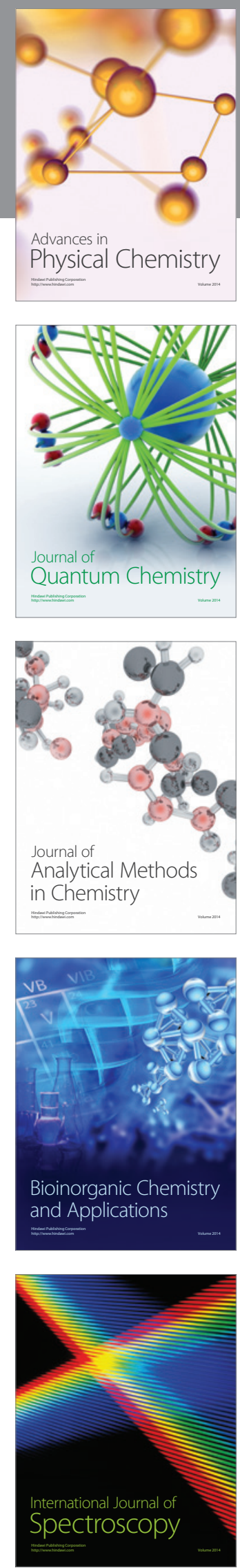